\title{
Multilocus phylogeny, species age and biogeography of the Lesser Antillean anoles
}

\author{
Roger S. Thorpe ${ }^{\mathrm{a}, *}$, Axel Barlow ${ }^{\mathrm{b}}$, Yann Surget-Groba ${ }^{\mathrm{c}}$, Anita Malhotra ${ }^{\mathrm{a}}$ \\ a School of Biological Sciences, College of Natural Sciences, Bangor University, Deiniol Road, Bangor LL57 2UW, UK \\ ${ }^{\mathrm{b}}$ Institute for Biochemistry and Biology, University of Potsdam, Karl-Liebknecht-Str. 24-25, 14476 Potsdam (Golm), Germany \\ ${ }^{\mathrm{c}}$ Institut des Sciences de la Foret Temperee, Universite du Quebec en Outaouais, 58 rue Principale, Ripon, QC JOV 1VO, Canada
}

\section{A R T I C L E I N F O}

\section{Keywords:}

Anolis

Multilocus phylogeny

Lesser antilles

Species age

Species turnover

Island colonization

\begin{abstract}
A B S T R A C T
Lesser Antillean anoles provide classic examples of island radiations. A detailed knowledge of their phylogeny and biogeography, in particular how the age of species relate to the ages of their respective islands and the age of their radiation, is essential to elucidate the tempo and mechanisms of these radiations. We conduct a large-scale phylogenetic and phylogeographic investigation of the Lesser Antillean anoles using multiple genetic markers and comprehensive geographic sampling of most species. The multilocus phylogeny gives the first well-supported reconstruction of the interspecific relationships, and the densely sampled phylogeography reveals a highly dynamic system, driven by overseas dispersal, with several alternative post-dispersal colonisation trajectories. These radiations currently occupy both the outer-older (Eocene to Miocene), and the inner-younger ( $<8$ mybp), Lesser Antillean arcs. The origin of these radiations corresponds with the age of the ancient outer arc. However, the ages of extant species (compatible with the age of other small terrestrial amniotes) are much younger, about the age of the emergence of the younger arc, or less. The difference between the age of the radiation and the age of the extant species suggests substantial species turnover on older arc islands, most likely through competitive replacement. Although extant anoles are extremely speciose, this may represent only a fraction of their biodiversity over time. While paraphyly enables us to infer several recent colonization events, the absence of the younger arc islands and extant species at the earlier and middle stages of the radiation, does not allow the earlier inter-island colonization to be reliably inferred. Reproductive isolation in allopatry takes a very considerable time (in excess of $8 \mathrm{my}$ ) and sympatry appears to occur only late in the radiation. The resolved multilocus phylogeny, and relative species age, raise difficulties for some earlier hypotheses regarding size evolution, and provide no evidence for within-island speciation.
\end{abstract}

\section{Introduction}

Island archipelagoes tend to be biodiversity hotspots (Myers et al., 2000), and have been the focus of many evolutionary studies. The production of that biodiversity (that is, the radiation of a group in an archipelago by classical geographic Darwinian evolution) can be thought of as loosely following a series of stages. First, the initial colonization of an island in the archipelago; second, the dispersal among islands, third the divergence of the various isolated (allopatric) island forms into separate species; and last the continued inter-island colonization resulting in independent species living in sympatry (Losos and Ricklefs, 2009). The anoles in the Lesser Antillean archipelago provide examples of island radiations where the tempo and mode of this process can be studied. Here, we investigate these radiations using a well-resolved multilocus molecular phylogeny, and densely sampled phylogeography, to elucidate these processes and expose the utility and limitations of these methods.

Anoles are small, neotropical/subtropical, insectivorous tree lizards that are the subject of numerous evolutionary and ecological studies (Losos, 2009). The genus (sensu lato) is very speciose, and we follow Losos (2009) and Poe (2013) in treating Anolis as a single genus with the main clades recognised as series (but see Nicholson et al., 2012, and Poe et al., 2017). The northern Lesser Antilles (Dominica northwards) are inhabited by the bimaculatus series, and the southern Lesser Antilles (Martinique southwards) and associated islands, are inhabited by the roquet series (Fig. 1). We use the term series, because of its convenience in distinguishing between various phylogenetic levels; for example the name roquet is used at three levels, 1) for the roquet series occupying the southern Lesser Antilles, 2) for the roquet complex that includes $A$. extremus from Barbados, and 3 ) for the nominal species $A$. roquet on Martinique.

\footnotetext{
* Corresponding author.

E-mail address: r.s.thorpe@bangor.ac.uk (R.S. Thorpe).
} 

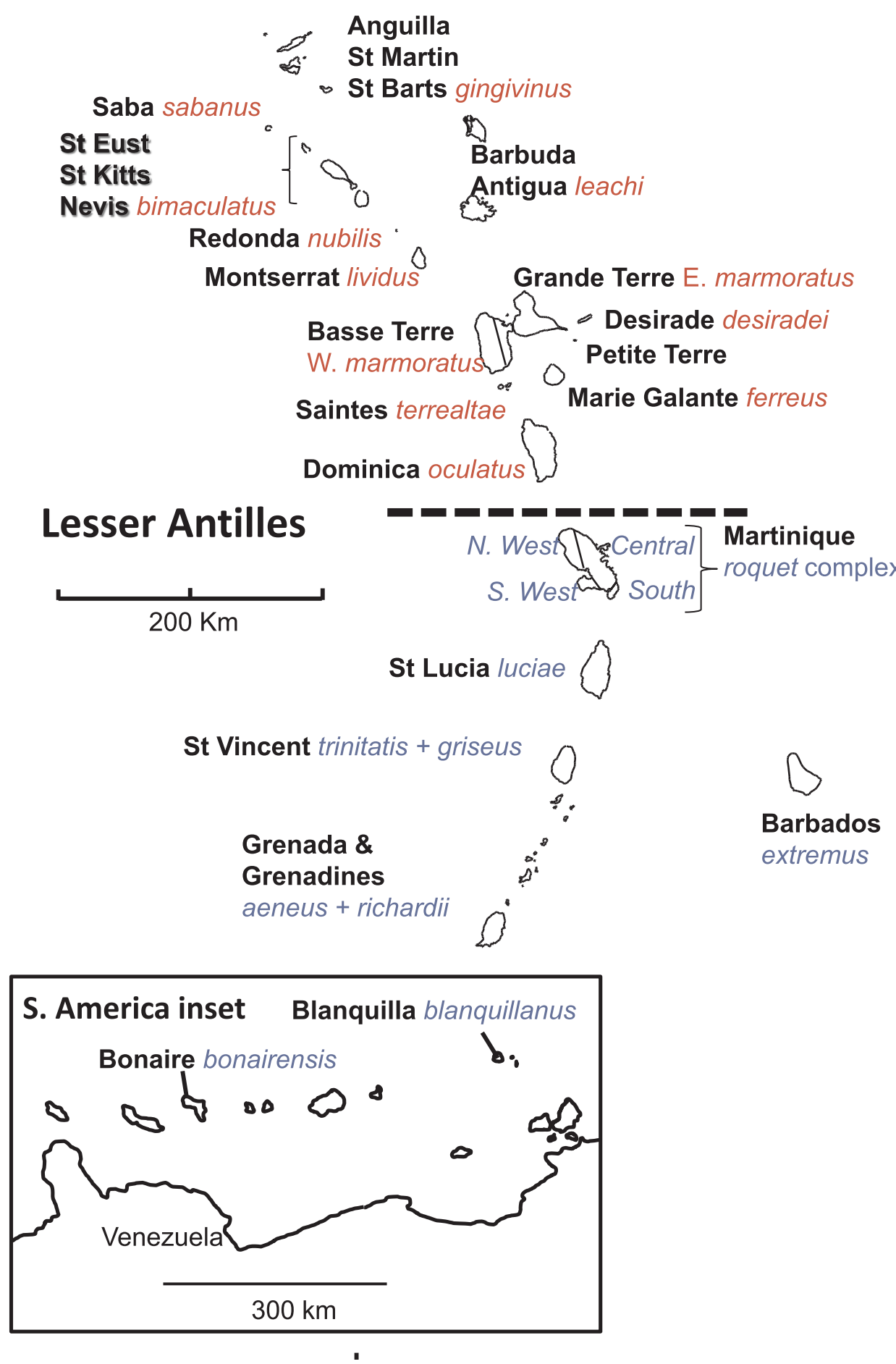

Fig. 1. Islands (in bold) and Anolis species (in italics) in the Lesser Antilles and associated islands. The bimaculatus series is north, and the roquet series, south of the dashed line. The insert shows Bonaire and Blanquilla off the South American coast. The wattsi complex is not included.

Phylogenetic studies (e.g. Nicholson et al., 2005) show that the Lesser Antillean bimaculatus and roquet series are as distantly related as anoles can be, and must have colonised this island chain independently. Both roquet and bimaculatus series are monophyletic, and exclusively Lesser Antillean, in the sense that they do not naturally have extant members in South America, or Greater Antilles, respectively. They do however, have sister taxa in South/Central America and the Greater Antilles respectively. This suggests that they may be the product of single colonizations of the Lesser Antilles (northern bimaculatus from the Greater Antilles, and southern roquet from South America), with subsequent divergence within their mutually exclusive northern and southern sections of the island chain.

The Lesser Antilles are composed of two volcanic arcs, which are superimposed from Martinique southwards. The older outer arc is Eocene to Miocene in origin (Wadge, 1994) and is currently represented by relatively low elevation islands, while the younger, inner arc is composed of mountainous islands that arose between 8 my ago in the late Miocene and the present (Bouysse, 1984), with most islands being 5 my old or younger (Briden et al., 1979). Both arcs are a product of subduction of the Atlantic Ocean crust under the Caribbean plate 
(Maury et al., 1990), with a subsequent independent volcanic origin of each island. The exceptions to this are Barbados, which is an accretionary prism (Speed, 1994), and the very ancient La Desirade (Briden et al., 1979). Also, two species from the roquet series are found south of the Lesser Antilles on continental shelf islands off the South American coast (Blanquilla and Bonaire). In any event, although the situation may be complicated by instances of island coalescence, the islands and island banks (e.g. St Kitts/Nevis bank) have generally arisen independently from the sea over time (Surget-Groba and Thorpe, 2013), so that overseas inter-island colonization is a dominant feature of the biogeography of these anoles.

Each Lesser Antillean island, or island bank, has either one or two endemic anole species, with no significant island or islet uninhabited (Fig. 1). Females may lay a series of single eggs every six weeks or so, with adults living a few years. There can be high population densities (Malhotra and Thorpe, 1991) and population turnover, and aspects of their life history (e.g. sperm storage and multiple inseminations) are compatible with a facility to colonize among islands and rapidly expand population size (Eales et al., 2010). Even so, these are low-vagility animals, with the per-generation gene exchange among islands effectively close to zero compared to the massive population turnover within an island (see also Reynolds et al., 2017). Numerous studies (Thorpe et al., 2015 and references therein) have shown that while there may be distinct phylogeographic divisions, and (largely unrelated) geographic variation in quantitative traits within an island species, morphological continuity among geographic sites testifies to their conspecificity (see, however, Thorpe et al., 2010 for Martinique).

Thus, Lesser Antillean anoles generally represent a system in which allopatric species are isolated from one another on separate islands/ island banks with deep sea between, with the potential for gene flow between species effectively zero throughout their entire evolutionary histories. Where two species occur in sympatry on a single island, they maintain morphological distinctiveness in widespread syntopy and without evidence of gene flow (Thorpe et al., 2015) and can therefore be considered to have independent evolutionary trajectories. In these cases, phylogenetic studies have shown that these island/island-bank species are mutually monophyletic. The exceptions to this general rule are multispecies complexes (roquet and marmoratus complexes), where precursor islands may coalesce resulting in secondary contact of previously allopatric "species", and nominal species may be paraphyletic (Materials and Methods).

The Lesser Antillean anole radiations have been used to study character displacement and alternative theories of size evolution (Losos, 2009), infer colonization sequence (Stenson et al., 2004; Losos, 2009), mechanisms of speciation (Thorpe et al., 2010), and the tempo and mode of radiations. These studies have been limited by poorly resolved phylogenies and poor sampling of many island species. Here we provide a well resolved, multilocus (mtDNA and five nDNA genes) phylogeny and, in a supporting analysis, dense sampling of numerous species to give a robust estimate of within-species age. We use these analyses to

(1) investigate the phylogeny to test for evidence of within-island speciation, the independent origin of large size, and investigate paraphyly and the status of allospecies:

(2) investigate the evolutionary and geological timescale to compare radiation and island arc age, individual island and species age, and test the reliability of estimating species age by interspecies divergence:

(3) investigate species age and relationships to test if extant Lesser Antillean anole species are atypically ancient or have a typical age for comparable species, consider alternative scenarios for the radiation-age versus species-age discrepancy including species turnover, and elucidate colonization sequence:

and (4) consider potential dispersal outcomes including the timing of reproductive isolation and sympatry.

\section{Materials and methods}

\subsection{Molecular methods}

DNA sequences consisted of published sequences (Thorpe et al., 2015, and references therein) and novel sequences generated for this study. Total DNA was extracted from autotomized tail tip tissue using a high salt method (Aljanabi and Martinez, 1997). Fragments of the mitochondrial cytochrome $b$ (cyt b) gene and protein coding sequences of the nuclear genes $3^{\prime}$ nucleotidase (NT3), prolactin receptor (PRLR), G protein-coupled receptor 149 (R35), recombination activating gene 1 (RAG1), and a partial intron of the Rhodopsin gene, were then PCR amplified using the cyt b primers in Thorpe et al. (2015); the PRLR and NT3 primers in Townsend et al. (2008); the R35 primers in Leaché (2009); the RAG1 primers Mart_FL1 and Amp_R1 described in Crottini et al. (2012) and Hoegg et al. (2004); and the Rhodopsin primers Rod3 and Rod4 in Glor et al. (2004). Reactions were performed in $11 \mu \mathrm{l}$ volumes, comprising ABgene ReddyMix ${ }^{\mathrm{TM}}$ PCR Master Mix (cat. no. AB0575/LD/A), $0.27 \mu \mathrm{M}$ of each primer and $\sim 10-20 \mathrm{ng}$ of template DNA. Products from PCR were cleaned using the enzymes exonuclease 1 and thermo-sensitive alkaline phosphatase, and direct sequencing carried out by Macrogen Inc. (dna.macrogen.com) using both forward and reverse primers. Sequence chromatograms were proof-read, aligned and protein coding sequences checked for unexpected stop codons or frameshift mutations using the software CodonCode Aligner version 3.5.6. See Appendix A in supplementary materials for details of the samples and alignments.

\subsection{Phylogenetic methods}

There were two primary phylogenetic analyses. The first (Analysis 1) aims to produce a well resolved interspecific phylogeny, the second (Analysis 2) aims to produce a robust estimate of the age of individual species in relation to the age of the appropriate anole radiation (series or clade).

\subsubsection{Phylogenetic methods Analysis 1: Multilocus tree}

In order to maximize the possibility of producing a phylogenetic tree with resolved inter-specific relationships, the mtDNA gene cytochrome $b$, and five single-copy nuclear genes (NTF3, PRLR, R35, RAG1, Rhodopsin) were used. Previous studies (Thorpe et al., 2015 and references therein) have revealed the phylogeographic structure within well sampled individual species. For Analysis 1, where there are numerous collection sites within a species, sites were selected to represent these major phylogeographic regions. Other species have fewer collection sites per island. The geographic sampling of DNA sequences is shown in Fig. 2. All species from the roquet series, together with $A$. oculatus, and A. marmoratus from the bimaculatus series, have multiple sample sites per species. All other species from the bimaculatus series are represented by at least one site per island/islet.

All well-recognized, nominal, species are included for both series, and putative species from precursor islands, e.g., the four lineages on Martinique in secondary contact after the coalescence of the precursor islands (Thorpe et al., 2010), are treated as separate entities. For the roquet series these are $A$. luciae from St Lucia, A. trinitatis (smaller) and A. griseus (larger) from St Vincent, A. aeneus (smaller) and A. richardii (larger) from Grenada, A. bonairensis from Bonaire, A. blanquillanus from Blanquilla, $A$. extremus from Barbados, and NW Martinique $A$. roquet, SW Martinique $A$. roquet, S Martinique $A$. roquet and central Martinique $A$. roquet from Martinique. The Barbados species A. extremus (nested within Martinique roquet) and the four Martinique lineages are hereafter referred to as the roquet complex. The bimaculatus series excludes the small bodied wattsi clade, which is sister to the remaining larger bodied bimaculatus series (Poe et al., 2017). The species included are, $A$. leachi from Barbuda and Antigua, $A$. bimaculatus from the St Kitts and Nevis bank, $A$. gingivinus from Anguilla and St Martin, $A$. terraealtae 

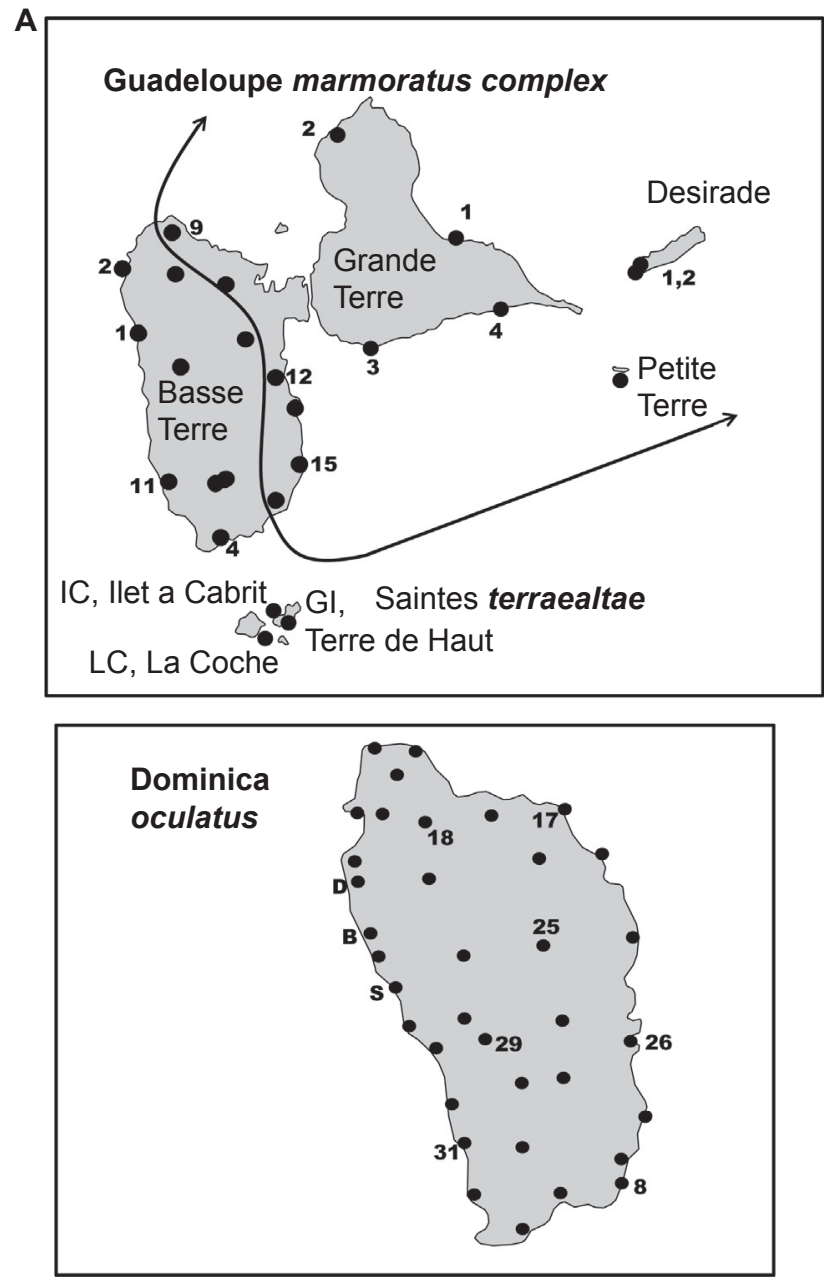

Fig. 2. Islands with multiple sampling localities. $2 \mathrm{~A}$ bimaculatus series. $2 \mathrm{~B}$ roquet series. Not to scale. Localities employed in Analysis 1 are numbered; additional localities (Analysis 2) are un-numbered. The lines in Guadeloupe and Martinique indicate the components of the marmoratus and roquet complexes respectively. On the multiple species islands of St Vincent and Grenada A. trinitatis, $A$. griseus, $A$, aeneus and $A$. richardii localities are indicated by $\mathrm{t}, \mathrm{g}$, a and $\mathrm{r}$ respectively. The identity of all localities and the primary lineages of species are found in Thorpe et al. (2015) for A. marmoratus on Basse Terre, A. oculatus, A. trinitatis, A. richardii, A. aeneus and A. luciae; in Thorpe et al. (2005) for A. extremus; in Thorpe and Stenson (2003) for the roquet complex on Martinique; in Thorpe (2017) for A. bonairensis; and in Appendix B in supplementary materials for A. blanquillanus and eastern A. marmoratus.

from Les Saintes group of small islands, A. oculatus from Dominica, A. ferreus from Marie Galante, A. lividus from Montserrat, A. nubilis from Redonda, $A$. sabanus from Saba, $A$. desiradei from La Desirade, western A. marmoratus from west and central Basse Terre, eastern A. marmoratus from Grande Terre, eastern Basse Terre, and Petite Terre. The population from the islets of Petite Terre off Grande Terre are not recognized in this study as a nominal species, but are sampled. The populations from the islets of Îlet-à-Kahouanne and Tête-à-Anglais off northern Basse Terre are not recognized as nominal species and not included. The multispecies complex of $A$. sabanus, eastern $A$. marmoratus, western $A$. marmoratus, and $A$. desiradei is hereafter referred to as the marmoratus complex (Fig. 2).

Phylogenetic analysis of the concatenated cyt $b$ and nuclear datasets were conducted using a Bayesian method with a Yule tree prior in BEAST v. 1.7.4. (Drummond et al., 2012). Heterozygous positions in nuclear sequences were treated as missing data (Appendix A in supplementary materials). Datasets were partitioned by gene and each assigned separate molecular clock and substitution models, with the latter selected under the Bayesian Information Criterion in MEGA5 (Tamura et al., 2011). Preliminary runs with relaxed clock models failed to reject zero variation in substitution rates along individual branches of the tree for each gene, and so strict clock models were utilized. MCMC chains ran for sufficient length to achieve convergence and sufficient sampling of all parameters (ESS > 200), verified using the program TRACER v. 1.6 (Rambaut et al., 2014). The maximum clade-credibility (MCC) tree was obtained and annotated with relevant statistics from the posterior sample of trees using the program TREEANNOTATOR (distributed with the BEAST v. 1.8.2 package). Additional phylogenetic estimates were also conducted under maximum likelihood (ML) using RAxML-HPC2 8.2.3 (Stamatakis, 2014) on the CIPRES Portal (Miller et al., 2010) using the iguanid Polychrus marmoratus as the outgroup. The dataset was partitioned as described above and the ML tree estimated using a GTR + G models and clade support assessed by 500 bootstrap replicates using a GTR + CAT model (which approximate the GTR + G model while offering greatly increased computational speed). We additionally analysed the aligned nuclear sequences using identical methods to check for consistency between relationships inferred using only nuclear sequences with those inferred using the complete dataset.

\subsubsection{Phylogenetic methods Analysis 2: Molecular dating}

The extent of molecular divergence between a pair of extant species may give an upper bound to the time of their divergence, but this will tend to be exaggerated by deep lineage coalescence, and especially by the extinction of any intermediate species. The latter may be a particular problem in radiations with considerable species turnover and lead to a gross overestimation of the age of a species. Assuming complete lineage sorting following colonization, and no subsequent bottlenecking, the extent of divergence within a species should give a more realistic estimate of time of colonization and origin, but will be underestimated by lineage extinction resulting from genetic drift, and or under-sampling within the species. The latter can be managed by comprehensively sampling the geographic range of a species, as this will minimize the possibility of not sampling a major divergent phylogeographic lineage. For this analysis, we employed just the cyt $b$ gene, because mtDNA will more closely match population divergence and be less prone to incomplete lineage sorting due to lower effective population size $(\mathrm{Ne})$ in comparison to nuclear markers. Moreover, it allowed us to efficiently maximize the number of sample sites (geographic localities) with sequences, thereby minimizing the critically important problem of under-sampling within-species divergence. However, the inferential power of using this single gene is limited as one cannot distinguish among demographic factors such as bottlenecks, rapid population expansion and selective sweeps (Pavlidis and Alachiotis, 2017). Similarly, the single gene tree may not represent the species tree and be confounded by interspecific hybridization. However, successful interspecific hybridization in anoles is in any event rare (Losos, 2009), and unknown on Lesser Antillean islands (in natural sympatry, or with introduced species). Moreover, here we have a parallel multilocus species tree for comparison of well supported nodes (Analysis 1). Consequently, the above advantages of mtDNA outweigh these potential disadvantages.

In line with this approach, the number of sites per species was maximized for Analysis 2 (Fig. 2). Sample site numbers for Analysis 2 that are not also used in Analysis 1 are given for each species in Thorpe et al. (2015), or Appendix B in supplementary materials and samples are geo-referenced in Appendix A in supplementary materials. This gave us dense to very dense sampling for all the roquet series species (even the small island of Blanquilla has several sampled sites and St Lucia has over 80), with $A$. oculatus (Dominica), and the western and eastern $A$. marmoratus from the bimaculatus series, being well sampled.

We calibrated our Analysis 2 phylogenetic tree by constraining the age of the tree root. This age was estimated by reanalysis of the dataset and calibrations used in a previous phylogenetic study of iguanian 


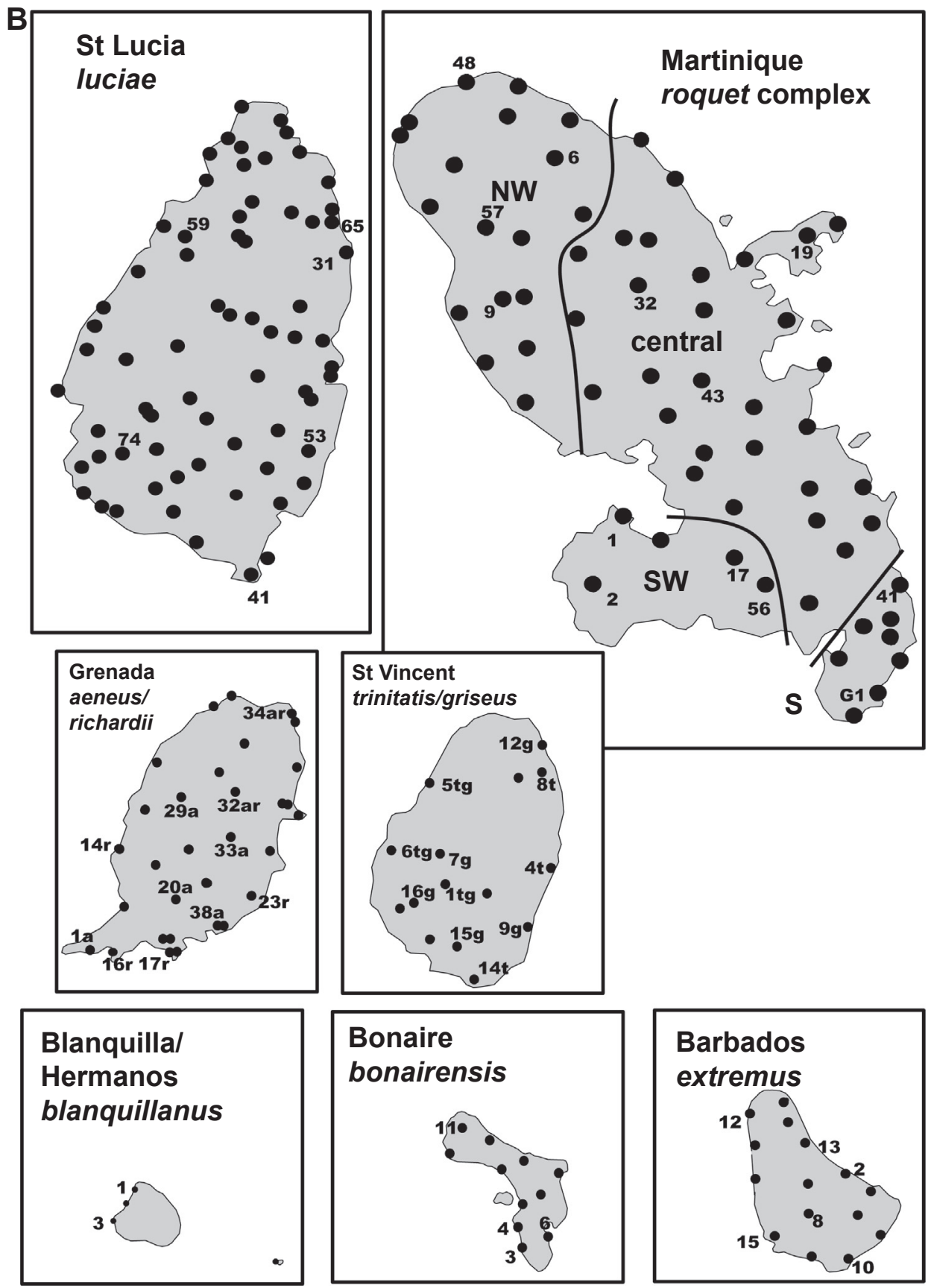

Fig. 2. (continued)

lizards (Townsend et al., 2011) based on 29 nuclear genes and 18 fossil calibrations. In order to recover the mean age of the Anolis crown group, this analysis was replicated with additional Anolis representatives encompassing the basal divergence of the genus. Based on this result we calibrated the Anolis tree root using a normal prior with a mean age of 44.9 mybp and a 95\% confidence interval of 36.1-53.3my (T. Townsend, Pers. Comm.). This is closely compatible with Prates et al.'s (2015) dating of the divergence of major anole groups (Norops, Anolis, Dactyloa) at $49 \mathrm{my}$ (HPD $=38-63 \mathrm{My})$. These estimates are lower than of Nicholson et al (2012) who estimate the origin of anoles at 95 my, but see Prates et al (2015) for comments on the reliability of the dating estimates employed. Selection of substitution, molecular clock and tree models, as well as analysis and processing of the posterior sample of trees, was as described for Analysis 1.

\section{Results}

\subsection{Analysis 1: Multilocus tree}

We generated a combined total of $2453 \mathrm{bp}$ DNA sequence from five single copy nuclear genes ( $621 \mathrm{bp}$ of NTF3, $516 \mathrm{bp}$ of PRLR, $344 \mathrm{bp}$ of R35, 729 bp of RAG1, 330 bp of Rhodopsin), for the numbered sites in Fig. 2, together with 1041 bp mitochondrial DNA (cyt b). For these sites the nuclear and cyt $\mathrm{b}$ alignments contained $13 \%$ and $11 \%$ missing data, respectively (Appendix A in supplementary materials). Tree data is available via the Bangor University data repository (https://research. bangor.ac.uk/portal/en/researchdata/multilocus-phylogeny-speciesage-and-biogeography-of-the-lesser-antillean-anoles(f89945c0-43414f87-a18e-60b19a456ce2).html).

Concatenated analysis of nuclear sequences without mitochondrial DNA gave a phylogeny with well supported interspecific relationships 


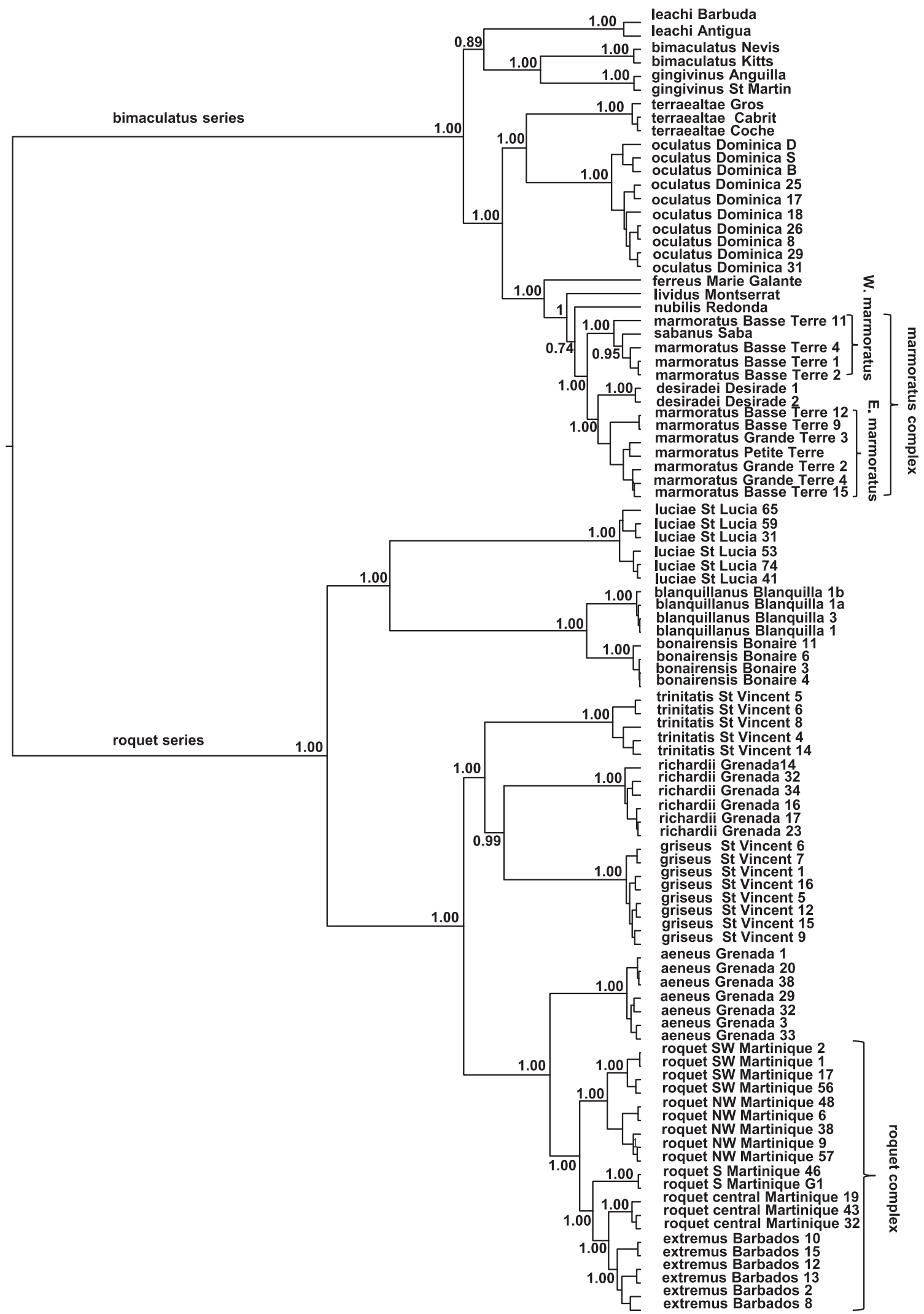

Fig. 3. Analysis 1. Total evidence phylogeny of Lesser Antillean anoles based on concatenated mitochondrial and nuclear genes. Number at nodes indicates posterior clade probabilities at the level of nominal species, putative precursor "species", and complexes, or above. The species name, island and (where appropriate) locality number are indicated at terminal nodes. Branch lengths indicate relative clade divergence times, assuming a shared phylogeny among loci. 
above the level of species complexes (Appendix C in supplementary materials). While concatenated analysis of all sequences provided complete resolution (posterior clade probabilities all $>0.95$ ) of interspecific relationships within the roquet series and almost complete resolution within the bimaculatus series (except at the nubilis and marmoratus node) (Fig. 3). The topology was confirmed by the congruent maximum likelihood tree (Appendix D in supplementary materials). The Analysis 1 phylogeny supported the monophyly of almost all nominal species with multi-individual sampling, except where there are multispecies complexes. In the bimaculatus series, the marmoratus complex has A. sabanus (Saba) nested within the western marmoratus (Basse Terre) lineage rendering it paraphyletic, and $A$. desiradei as sister to the eastern marmoratus (Grande Terre plus) lineage. The roquet complex contains A. extremus (Barbados) nested among the Martinique "species" from the precursor islands, with the central Martinique $A$. roquet as the sister lineage.

Within the roquet series, a major division exists between the lineage (A. luciae, bonairensis, blanquillanus) and the lineage (A. roquet, extremus, trinitatis, aeneus, richardii, griseus). Notably these two primary lineages within the roquet series do not inhabit geographically distinct regions. The lineage (A. roquet, extremus, trinitatis, aeneus, richardii, griseus) then splits into a lineage (A. trinitatis, richardii, griseus) from the more southerly LA islands of St Vincent and Grenada, and a more widely distributed lineage (A. roquet, extremus, aeneus) from Martinique, Barbados and Grenada. The large species of $A$. richardii and A. griseus, from Grenada and St Vincent respectively, are sister taxa, while the small species (A. aeneus, A. trinitatis) are not. Neither of the large and small pairs on St Vincent (small A. trinitatis, large A. griseus), and Grenada (small $A$. aeneus, large $A$. richardii) are sister species. All these major divisions of the roquet series are well supported.

However, in the bimaculatus series there are some geographic trends. The northern species A. leachi, A. bimaculatus, and A. gingivinus (from Barbuda/Antigua, St Kitts/Nevis, Anguilla/St Martin respectively) group together, as do those from the more southerly regions of the bimaculatus series range, that is, A. terraealtae (Les Saintes) and A. oculatus (Dominica). The species from the more central part of the bimaculatus series range, A. ferreus, A. lividus, A. nubilis, and the marmoratus complex, also group together.

One of the purposes of the multilocus Analysis 1 is to contribute to defining the evolutionary units or "species" to be dated in Analysis 2. For the roquet series the nominal species A. luciae, A. trinitatis, A. griseus, A. aeneus, A. richardii, A. bonairensis, and A. blanquillanus are reciprocally monophyletic and on this criteria are not excluded from the dating in Analysis 2. Anolis extremus (Barbados) is nested inside the four major lineages of the roquet complex from Martinique in conformity with previous studies (Thorpe and Stenson, 2003; Thorpe et al., 2010; Surget-Groba and Thorpe, 2013). Investigations of the geology, phylogeography and population genetics of this complex elucidate how the four roquet "species" occupied four of the precursor islands (NW Martinique, SW Martinique, S Martinique and central Martinique) that have geologically recently joined to form current day Martinique resulting in secondary contact with varying degrees on introgression. The nominal species A. extremus evolved on Barbados after having probably been colonized from the central Martinique precursor island. Consequently, these five reciprocally monophyletic lineages are regarded as independent entities for the purposes this study, and join the seven nominal species above in being eligible for dating in Analysis 2.

The species of the bimaculatus series are less well sampled and the situation is more complex. The Dominican species (A. oculatus) is monophyletic and is eligible for inclusion in the dating analysis. The situation with the marmoratus complex is less well studied than the roquet complex. Once again there appears to be two broad reciprocally monophyletic allospecies associated with precursor islands of Basse Terre and Grand Terre (although the Grande Terre plus outlying islands lineage now also occupies eastern Basse Terre). However, A. sabanus, while being distinctly different in appearance, is not reciprocally monophyletic with the Basse Terre lineage, but is nested within it. Moreover, A. desiradei and Grande Terre A. marmoratus are sister lineages nested within the marmoratus complex. The recognition of these allopatric species inevitably has arbitrary aspects, and this allows various interpretations of the evolutionary units to be dated.

\subsection{Analysis 2: Molecular dating}

We assembled a dataset of 459 mitochondrial DNA sequences from the roquet and bimaculatus series, comprising $1041 \mathrm{bp}$ of aligned cyt $\mathrm{b}$ sequence (all sites in Fig. 2 and Appendix B). For these sites the cyt b alignments contained 5\% missing data (Appendix A in supplementary materials). Tree data is available via the Bangor University data repository (https://research.bangor.ac.uk/portal/en/researchdata/ multilocus-phylogeny-species-age-and-biogeography-of-the-lesserantillean-anoles(f89945c0-4341-4f87-a18e-60b19a456ce2).html).

We found high levels of haplotype diversity. Sequences from 339 individuals of nine species in the roquet series yielded 319 unique cyt $b$ haplotypes. Reduced sampling for the bimaculatus series prevents a robust comparison, but the rate of haplotype discovery in the two wellsampled species suggests similar levels of diversity. The large-sample, single-gene Yule tree (Appendix E in supplementary materials) is generally congruent with the reduced-sample, multilocus tree from Analysis 1 (the well supported interspecific topology is congruent). However, details of the marmoratus complex from the bimaculatus series differ. Here, the western A. marmoratus lineage (Basse Terre) is no longer monophyletic, since two individuals from western Basse Terre join A. nubilis (Redonda) as an outgroup to the otherwise congruent marmoratus complex. Hence, the inclusion of western A. marmoratus as an evolutionary unit to be dated is compromised, as is the dating of the whole marmoratus complex, as these units include the nominal species A. nubilis in contradiction to the multilocus tree.

For the roquet series, the roquet complex is eligible to be dated, as potentially are the "species" NW A. roquet, SW A. roquet, S A. roquet, central A. roquet, A. extremus, A. trinitatis, A. aeneus, A. richardii, A. griseus, A. luciae, A. bonairensis, and A. blanquillanus. However, the latter has to be excluded because there are too few samples within the species to adequately sample the diversity, and $S$ Martinique and central Martinique roquet have to be excluded because of the potential for bottlenecks reducing the within species diversity. Although the central Martinique lineage now occupies quite a large area, the lack of phylogeographic structure (Thorpe and Stenson, 2003; Thorpe et al., 2010), and relatively low diversity, is suggestive of bottlenecking. However, this still allows a strong sample of species to be dated within the roquet series. The situation with the bimaculatus series is less useful. The species A. leachii, A. bimaculatus, A. ferreus, A. nubilis, A. sabanus, and A. terraltae, are not sufficiently well sampled to allow robust dating based on within-species diversity. Moreover, the diversity of those on the smaller islands and islets (e.g. Redonda, Les Saintes) may be impacted by bottlenecking. Dating of some of the components of the marmoratus complex is also difficult given the complications explored above (incongruence, outliers and species limits).

The median and 95\% HPD of the approximate time to most recent common ancestor (TMRCA) dates are given in Table 1, and illustrated in Fig. 4. The age of the roquet series, based on within-series divergence is about 32 mybp, while the bimaculatus series, using the same criteria is younger at about 22 mybp. The age of the eligible species in the roquet series (NW A. roquet, SW A. roquet, A. extremus, A. trinitatis, A. aeneus, A. richardii, A. griseus, $A$. luciae, and $A$. bonairensis) are all under $5 \mathrm{my}$ with an mean age of $2.5 \mathrm{my}$. Hence, the well sampled individual species in the roquet series are very much younger than the series itself: on average only a thirteenth of the age of their series. Even the multispecies roquet complex is only $7.6 \mathrm{my}$ old, approximately a quarter of the age of its series.

The Dominican anole (A. oculatus) from the bimaculatus series is relatively young at just under $4 \mathrm{my}$ and the eastern $A$. marmoratus 
Table 1

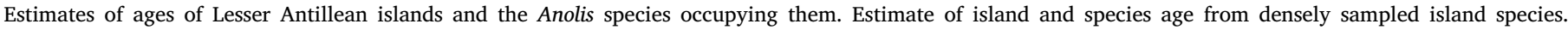

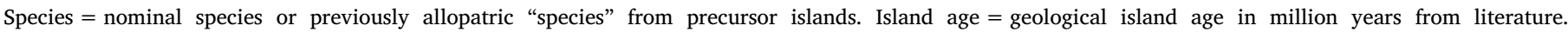

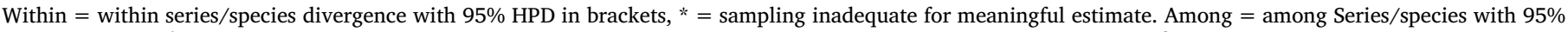

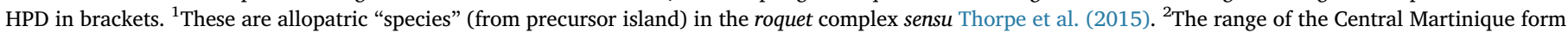

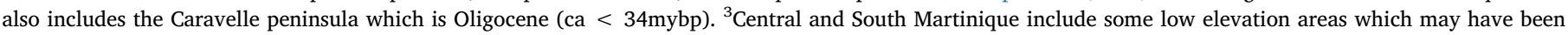

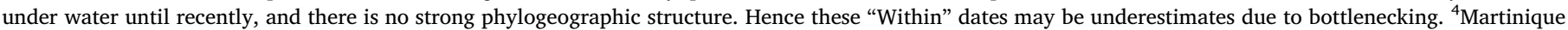

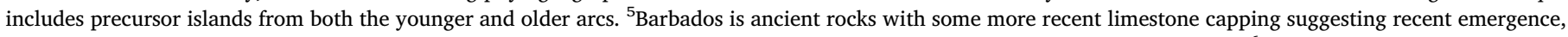

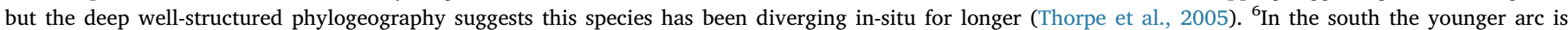

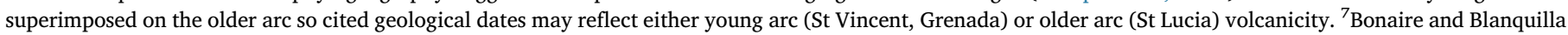

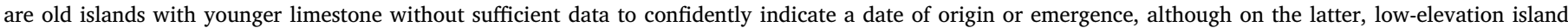

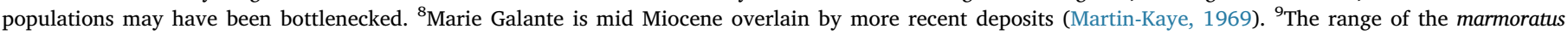

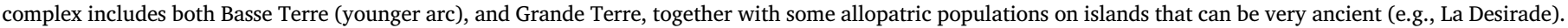

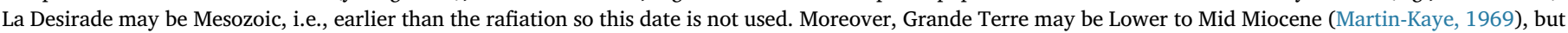

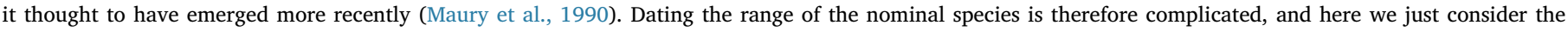

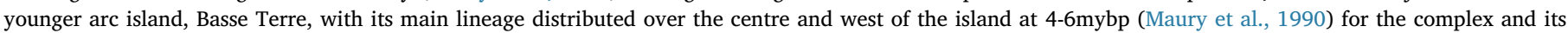

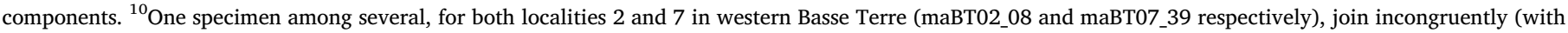

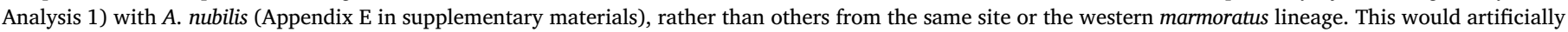

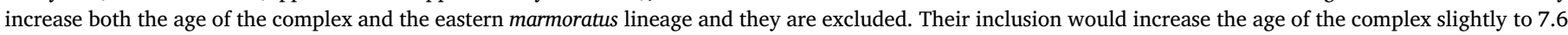
mybp.

\begin{tabular}{|c|c|c|c|c|c|}
\hline Island/series & Species & Island age & Reference & Yule Within & Yule Among \\
\hline roquet series & & & & $\begin{array}{l}31.60 \\
(23.8-39.1)\end{array}$ & $\begin{array}{l}43.6 \\
(34.8-52.6)\end{array}$ \\
\hline NW Martinique & NW Mart ${ }^{1}$ & 7.1 & Briden et al. (1979) & $\begin{array}{l}2.38 \\
(1.57-3.29)\end{array}$ & $\begin{array}{l}4.19 \\
(2.93-5.56)\end{array}$ \\
\hline SW Martinique & SW Mart ${ }^{1}$ & 8.3 & Briden et al. (1979) & $\begin{array}{l}1.73 \\
(1.07-2.45)\end{array}$ & $\begin{array}{l}4.19 \\
(2.93-5.56)\end{array}$ \\
\hline Central Martinique & Central Mart $^{1}$ & $12.8-15.9^{2}$ & Briden et al. (1979), Wadge (1994) & $\begin{array}{l}1.46 \\
(0.97-2.00)^{3}\end{array}$ & $\begin{array}{l}4.08 \\
(2.96-5.29)\end{array}$ \\
\hline S Martinique & S Mart ${ }^{1}$ & $<34$ & Wadge (1994) & $\begin{array}{l}1.40 \\
(0.86-1.97)^{3}\end{array}$ & $\begin{array}{l}5.94 \\
(4.35-7.65)\end{array}$ \\
\hline All Martinique & roquet & $<34^{4}$ & Wadge (1994) & $\begin{array}{l}7.56 \\
(5.65-9.65)\end{array}$ & $\begin{array}{l}10.1 \\
(7.40-12.81)\end{array}$ \\
\hline Barbados & extremus & -5 & Speed (1994), Thorpe et al. (2005) & $\begin{array}{l}3.35 \\
(2.37-4.33)\end{array}$ & $\begin{array}{l}4.08 \\
(2.96-5.29)\end{array}$ \\
\hline St Lucia & luciae & $18.3^{6}$ & Briden et al. (1979) & $\begin{array}{l}3.30 \\
(2.27-4.33)\end{array}$ & $\begin{array}{l}23.4 \\
(17.2-29.6)\end{array}$ \\
\hline St Vincent & trinitatis & $3.5^{6}$ & Maury et al. (1990) & $\begin{array}{l}4.23 \\
(2.99-5.64)\end{array}$ & $\begin{array}{l}15.4 \\
(1.5-19.6)\end{array}$ \\
\hline St Vincent & griseus & $3.5^{6}$ & Maury et al. (1990) & $\begin{array}{l}2.12 \\
(1.40-2.90)\end{array}$ & $\begin{array}{l}15.4 \\
(1.5-19.6)\end{array}$ \\
\hline Grenada & aeneus & $>5^{6}$ & Maury et al. (1990), Martin-Kaye (1969) & $\begin{array}{l}1.82 \\
(1.20-2.47)\end{array}$ & $\begin{array}{l}10.1 \\
(7.4-12.81)\end{array}$ \\
\hline Grenada & richardii & $>5^{6}$ & Maury et al. (1990), Martin-Kaye (1969) & $\begin{array}{l}2.44 \\
(1.66-3.26)\end{array}$ & $\begin{array}{l}19.9 \\
(15.0-25.1)\end{array}$ \\
\hline Bonaire & bonairensis & $-{ }^{7}$ & & $\begin{array}{l}1.21 \\
(0.74-1.78)\end{array}$ & $\begin{array}{l}7.22 \\
(5.10-9.59)\end{array}$ \\
\hline Blanquilla & blanquillanus & $-{ }^{7}$ & & $\begin{array}{l}0.60 \\
(0.33-0.91)\end{array}$ & $\begin{array}{l}7.22 \\
(5.10-9.59)\end{array}$ \\
\hline bimaculatus series & & & & $\begin{array}{l}22.1 \\
(16.8-27.8)\end{array}$ & $\begin{array}{l}43.6 \\
(34.8-52.6)\end{array}$ \\
\hline St Martin Bank & gingivinus & 37 & Briden et al. (1979), Maury et al. (1990) & * & $\begin{array}{l}14.5 \\
(9.91-20.0)\end{array}$ \\
\hline Saba & sabanus & 0.4 & Roobol and Smith (2004) & * & $\begin{array}{l}2.12 \\
(1.42-2.92)\end{array}$ \\
\hline Kitts Nevis bank & bimaculatus & 3.4 & Maury et al. (1990) & * & $\begin{array}{l}14.5 \\
(9.91-20.0)\end{array}$ \\
\hline Antigua Barbuda Bank & leachi & 40 & Briden et al. (1979) & * & $\begin{array}{l}19.6 \\
(14.9-24.6)\end{array}$ \\
\hline Redonda & nubilis & $<1.5$ & Maury et al. (1990) & * & $\begin{array}{l}5.96 \\
(4.21-7.97)\end{array}$ \\
\hline Montserrat & lividus & 4.4 & Briden et al. (1979), Maury et al. (1990) & * & $\begin{array}{l}9.37 \\
(6.95-12.0)\end{array}$ \\
\hline Illes des Saintes & terraealtae & 4.7 & Maury et al. (1990) & * & $\begin{array}{l}13.6 \\
(10.1-17.3)\end{array}$ \\
\hline Marie Galante & ferreus & -8 & & * & $\begin{array}{l}12.0 \\
(8.87-15.2)\end{array}$ \\
\hline Guadeloupe (excl I d Saintes, Marie Galante) & marmoratus complex ${ }^{9,10}$ & $(4-6)$ & Maury et al. (1990) & *6.91 (5.12-8.74) & $\begin{array}{l}7.61 \\
(5.55-9.81)\end{array}$ \\
\hline Grande Terre + East BT + Petite Terre + Desirade & Eastern marmoratus + desiradei ${ }^{9}$ & $(4-6)$ & Maury et al. (1990) & $5.74(4.12-7.37)$ & $\begin{array}{l}6.91 \\
(5.12-8.74)\end{array}$ \\
\hline Desirade & desirade $^{9}$ & mesozoic & Maury et al. (1990) & * & $\begin{array}{l}5.74 \\
(4.12-7.37)\end{array}$ \\
\hline Grande Terre + eastern BT + Petite Terre) & Eastern marmoratus ${ }^{9}$ & $(4-6)$ & Maury et al. (1990) & $4.40(3.10-5.77)$ & $\begin{array}{l}5.74 \\
(4.12-7.37)\end{array}$ \\
\hline
\end{tabular}


Table 1 (continued)

\begin{tabular}{|c|c|c|c|c|c|}
\hline Island/series & Species & Island age & Reference & Yule Within & Yule Among \\
\hline Basse Terre (+ Saba) & Western marmoratus ${ }^{10}$ & $4-6$ & Maury et al. (1990) & $3.62(2.48-4.82)$ & $\begin{array}{l}6.91 \\
(5.12-8.74)\end{array}$ \\
\hline Dominica & oculatus & $<5$ & Maury et al. (1990), Martin-Kaye (1969) & $3.98(2.85-5.18)$ & $\begin{array}{l}13.6 \\
(10.1-17.3)\end{array}$ \\
\hline
\end{tabular}

lineage (Grande Terre plus offshore islets) dates at a very similar $4.4 \mathrm{my}$. If the incongruent $A$. nubilis + outliers are excluded, the western $A$. marmoratus lineage (western Basse Terre plus A. sabanus) is also a comparable 3.6 my old. The marmoratus complex is 6.9 my old if the $A$. nubilis + outliers are excluded, and 7.6 my if not. In any event there a few species to be robustly dated, but, once again, they are much younger than the age of the series (about a fifth depending on the definition of a "species").

\section{Discussion}

\subsection{Phylogeny}

Earlier molecular phylogenies of Lesser Antillean anoles relied heavily on mtDNA analyses (Creer et al., 2001; Stenson et al., 2004), although other data (allozymes for the former, microsatellites for the latter) were included. These studies of the bimaculatus (Stenson et al., 2004) and roquet (Creer et al., 2001) series were far less well resolved and supported than the current multilocus study, which has only one key node with relatively poor support (in the bimaculatus series) (Fig. 3). Even so there is broad congruence between the trees from these earlier studies and the multilocus tree. They do, however, differ in node support and in the important detail of the topology. A recent phylogeny of all extant Anolis species (Poe et al., 2017) failed to resolve the relationships within either roquet or bimaculatus series as the nodes were generally very poorly supported at this level. The bimaculatus and roquet phylogenies of Poe et al. (2017) are notably incongruent with the wellsupported phylogeny in this study.

There is evidence from Thorpe et al. (2010) and Surget-Groba et al. (2012), that there can be notable reduction in gene flow between populations from different habitat types within an island. However, this study does not provide phylogenetic/biogeographic evidence of withinisland speciation as neither the St Vincent (A. griseus and A. trinitatis), or Grenada (A. aeneus, A. richardii), species pairs are sister taxa to their

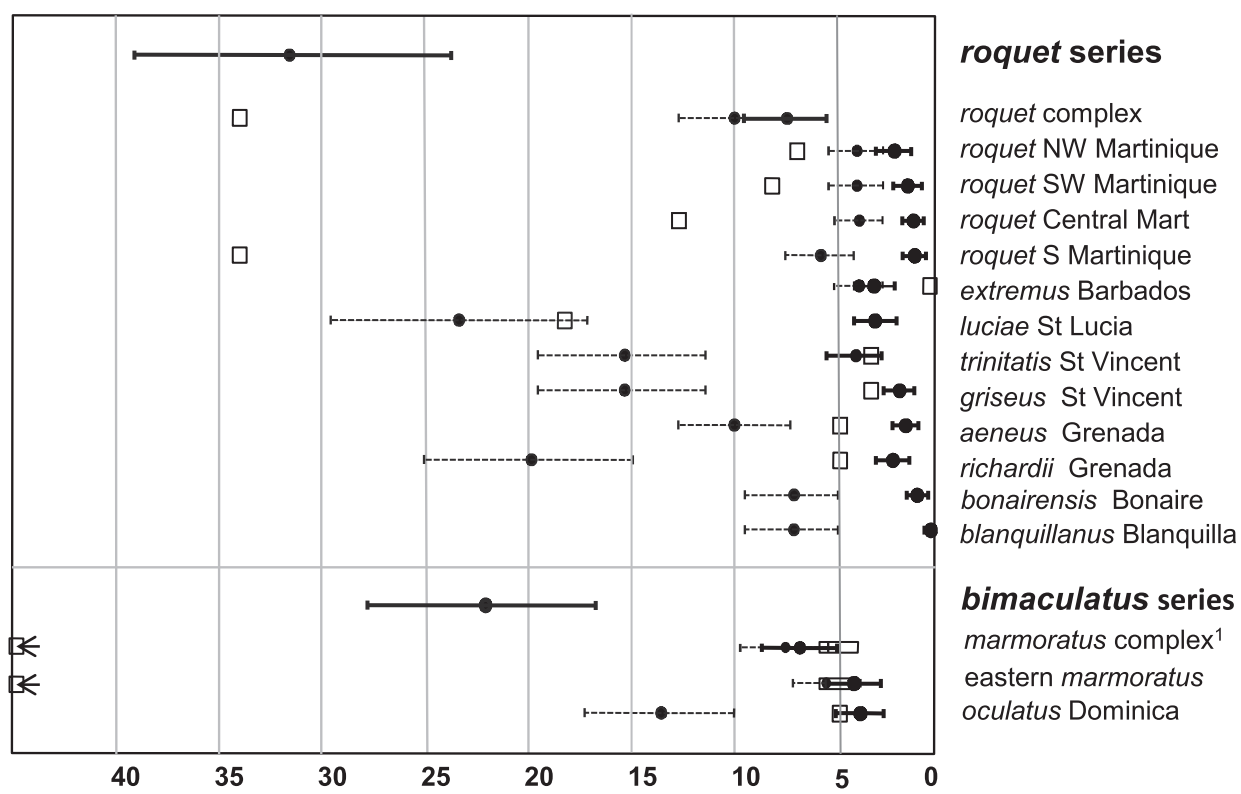

sympatric partner. One novel aspect of the resolved roquet series phylogeny is that the two larger roquet series species (A. griseus, St Vincent: A. richardii, Grenada) are sister taxa. This has implications for one of the better known aspects of Lesser Antillean anole biogeography. That is, the tendency for solitary anoles to be of intermediate size, while with sympatric pairs one tends to be larger and the other smaller. This is not absolute and, there is much more to be done in critically analyzing this phenomenon (Appendix $\mathrm{F}$ in supplementary materials). The recognition of allopatric species has an arbitrary element to it, which is exposed in both the roquet and marmoratus complexes. In the roquet complex, extremus from Barbados in nested among the previously allopatric lineages of the Martinique roquet nominal species. However, detailed population genetic study (Thorpe et al., 2010) shows that, generally, the different lineages within this nominal species exchange nuclear genes where they meet, as if they were conspecific. Anolis roquet on Martinique are regarded as nominally conspecific, while $A$. extremus, at least as phylogenetically divergent as most Lesser Antillean anoles, is found on distant Barbados (with no real prospect of genetic exchange with the Martinique populations) and is regarded as a sound nominal species. The situation in the less well-studied marmoratus complex from the bimaculatus series is even more complex. In a parallel situation to that in the roquet complex, there are two prospective precursor islands, Basse Terre and Grande Terre, which have recently approached, but are currently separated by a narrow, shallow, channel. As in the roquet complex these precursors have matching lineages (albeit with less lineage - precursor congruence) without evidence of complete genetic isolation where they meet on easterrn Basse Terre (Malhotra, 1992). Hence they are nominally conspecific as A. marmoratus. Also A. desiradei (La Desirade) is sister to the Grande Terre A. marmoratus lineage and is therefore nested inside the marmoratus complex. The La Desirade population is quite phylogenetically divergent to its sister lineage and here is regarded as a separate species. Although the Saban population is phylogenetically nested within Basse Terre A. marmoratus, it is morphologically distinct, and at a considerable geographic distance, and is

Fig. 4. Age of series, species complexes and of substantially sampled species in relation to island ages. The $\mathrm{x}$ axis represents time in millions of years before present. Series, species and their islands are listed on the right. For each species and series, points and thick solid bars show the median and 95\% HPD of the within species or series TMRCA, respectively. Points with thin dashed lines show the median and 95\% HPD of the divergence time between species and their nearest extant relative. Black squares show the ages of islands (with arrow indicating the offscale, possible, Mesozoic origin of La Desirade). ${ }^{1}$ See Table 1 for comments on the age of the marmoratus complex. 
regarded as the species A. sabanus. The population from the islets of Petite Terre (off shore to Grande Terre) are not phylogenetically divergent and we do not recognize these as separate species based on current available information. We did not include the populations from the islets of Îlet-à-Kahouanne and Tête-à-Anglais offshore to north Basse Terre, but see no published evidence to warrant their recognition as separate species (Meiri, 2016), and their phylogenetic relationships in Poe et al. (2017) are very poorly supported, make little geographic sense, and have little phylogenetic congruence with this, or previous, studies.

\subsection{The evolutionary and geological timescale}

The roquet and bimaculatus (excluding the wattsi group) series arose around 32 and 22 mybp respectively (Fig. 4, Table 1) after the origin of the older outer arc of Lesser Antillean islands in the Eocene to Miocene (Wadge, 1994), but before the origin of the younger inner arc (Bouysse, 1984). These geological dates are compatible with the invasion of the older arc from the south (S America) by the roquet series, and from the north (Greater Antilles) by the bimaculatus series, that is, step one in the above model. The subsequent invasion of the younger arc, once again by the roquet series in the south, and bimaculatus series in the north (step 2), could be achieved once the individual younger islands arose (circa $<8$ mybp). The difference in age of the two series is misleading, and it does not mean that the roquet series invaded the Lesser Antilles before the bimaculatus series. The wattsi complex of small northern anoles, which are phylogenetically (Poe et al., 2017) and morphologically distinct from the more morphologically robust bimaculatus series, are not included in this analysis. Their inclusion as part of the bimaculatus series would increase the diversity, and hence estimated age, of this series. The current north-south distribution of anoles in the Lesser Antilles is not shown in other animal groups and, given the dynamics of species turnover, we cannot necessarily assume that the relative distribution of these two series has been stable over time.

Based on within-species divergence, the extant species are estimated to have arisen after the geological origin of their respective islands (Fig. 4, Table 1, Appendix G in supplementary materials), as one would expect if the dating of the origin of both island and species is correct. One notable exception to this is A. extremus on Barbados. Barbados, unlike most other Lesser Antillean islands is not volcanic in origin, but is an accretionary prism covered by sedimentary rock. Although the underlying rock is ancient it is thought that it uplifted only recently (Bender et al., 1979) and the sedimentary capping suggests an age of emergence about a 0.5 to 1.0 milion years (Speed, 1994). There is substantial, hierarchal phylogeographic structure in A. extremus within Barbados (which is compatible with the slightly greater, between-species divergence, within the roquet complex) (Table 1). There are no suitable series of adjacent islets to act as alternative refugia with divergent populations from which mainland Barbados could be recolonized. Hence, the situation cannot readily be explained by anything other than at least some of the Barbados accretional prism being above water and inhabitable for much longer than $1 \mathrm{mybp}$. This is discussed in detail in Thorpe et al. (2005) and the dates for the roquet complex and its constituent lineages, including extremus from Barbados, are compatible with the previous focused studies (i.e. 95\% limits generally overlap).

Both the geological and molecular dating in the marmoratus complex and associated islands are complicated. La Desirade (Maury et al., 1990) is very ancient (predating the origin of all the lineages discussed here), while the dating of Grande Terre is complicated in a similar way to that of Barbados. That, is the underlying rocks of Grande Terre may be older, but it has a more recent sedimentary limestone cap and one cannot be sure that none of Grande Terre (or in this case, any other associated island or islet within easy colonization distance) was not above water and available for the marmoratus complex to inhabit. Consequently, the best date available is that of high elevation Basse
Terre dated at 4-6 mybp (Maury et al., 1990). These geological dates overlap the 95\% HPD values for the complex (all lineages), although they are below the mean value. However, here the phylogenetic information may be less reliable (in contradiction to the multilocus study) as another species (A. nubilis) and two Basse Terre specimens are included as outliers in this complex. This will exaggerate the withincomplex divergence, and once these are excluded the geological dates are more compatible with the within-complex, and within-"species" ages of 6.9 mybp for the marmoratus complex, and 3.6 mybp for the western A. marmoratus (Basse Terre, Saba).

One of the notable facets of Table 1 is the discrepancy between the age of a species estimated from within species divergence, compared to the age estimated from between-species divergence. While in some situations (such as the roquet complex) between-species divergence is no greater than within-species divergence than one would expect, in others the discrepancy is very notable. For example, the within-species divergence of $A$. luciae is likely to be reliable as it is based on exhaustive phylogeographic sampling, with little likelihood of bottlenecking having occurred on this large, high-elevation island. The within-species estimate for the age of $A$. luciae is only 3.3my (2.3-4.3 95\% HPD), while the between- species estimate is 23.4 (17.2-29.6 95\% HPD). While this is an extreme case, it nevertheless holds true as a generalization for situations where the phylogeny, phylogeographic sampling, and insensitivity to bottlenecking, allow meaningful estimates of within-and among species divergence (e.g., A. luciae, A. trinitatis, A. griseus, A. aeneus, A. richardii, and $A$. oculatus). It is clear that using between-species divergence to estimate species age could lead to a very misleading, gross over-estimation. On small, or low-elevation, islands bottlenecking can potentially greatly reduce within-species divergence so that species age cannot be reliably estimated from within-species divergence. In these situations, and where phylogeographic sampling does not allow an estimate of within-species divergence, then at least between species divergence may give an upper bound to the species age, however unrealistic it is as an estimate of the real age. However, considerable caution is required when workers use these inter-species estimates, because they can give ages much greater than the possible age of the island, emphasizing their unreliability.

\subsection{Species age and relationships and inter-island colonization}

The other, and perhaps most important revelation from Table 1, is the age of the species compared to the age of the entire series. While the series are Oligocene in origin, the species are Pleistocene to Pliocene, with even the large species complexes no older than very late Miocene. Even excluding underestimations due to potential bottlenecking, or inadequate sampling, the mean age of the species, at 2.5 and 4 my for roquet and bimaculatus series respectively, is compatible with northern hemisphere squamates of $3.3 \mathrm{my}$ (Dubey and Shine, 2010), the average persistence time of an island population of birds in the Lesser Antilles of about 2 my, (Ricklefs and Bermingham, 2007), and a modal age of 1-2 my for small North American mammals (Prothero 2014). Hence, the extant Lesser Antillean anole species are not atypically ancient.

Species age in Lesser Antillean anoles (bottlenecked excluded), being typical of such organisms, does not appear to be an underestimate that needs to be explained by a specific demographic factor, such as a selective sweep. Moreover, although we cannot rule out a selective sweep underestimating a given species age, it seems most unlikely that it would be ubiquitous across species. Consequently, other explanations need to be explored to explain the discrepancy between species age and the age of the radiations (with the above exclusions the average age of a species in the roquet series is only about $8 \%$ of the age of the series).

Anolis luciae from St Lucia, is used as an example, because 1) its close-to-average species age, 2) it is exhaustively sampled, and therefore unlikely to give an underestimate of species age due to inadequate sampling, and 3) it occurs on a large, high-elevation island, and has clear nested phylogeographic structure (Thorpe et al., 2015), making 
bottlenecking unlikely. St Lucia combines both young and old arc elements, and is dated at about 18 mybp (Briden et al., 1979), while the current extant species age is estimated at only 3.3 my old. Could St Lucia have been unoccupied by anoles prior to the establishment of $A$. luciae? This is most unlikely, given the complete occupation of every island and islet in the Lesser Antilles. This study provides no evidence of within-island speciation, so serially repeated in situ within-island speciation, with the new species repetitively replacing the old, is also an unlikely explanation. The most likely explanation is that there is species turnover with the island being occupied by a series of different anoles through time with colonizers replacing residents by competitive exclusion, perhaps (but not necessarily) with additional factors, such as disease and extreme physical events (volcanism, hurricanes), impacting the process. We are not aware of any anole extirpations due to recent hurricanes, volcanism or disease, and even the massive volcanic event in Dominica $28 \mathrm{ky}$ ago did not expurgate A. oculatus (Malhotra and Thorpe, 2000). These additional proximal reasons may be irrelevant to the broad picture of competitive replacement by new colonizers. Unfortunately, what fossil evidence there is of Lesser Antillean anoles (Kemp and Hadly 2016; references in Losos, 2009) is of little use in this context as the subfossils are too recent (Holocene) to distinguish between species longevity and species turnover, and species cannot be distinguished by multivariate analysis on the phenotypic traits employed (Bochaton et al., 2017). What emerges is that the current biogeographic pattern, in geological terms, is likely to be just a temporary time-slice of a very dynamic situation, with substantial species turnover throughout the long life of the radiations.

Species turnover has important implications, not least for attempts to understand the colonization sequence within the Lesser Antilles (i.e. step 2 inter-island colonization). As the bimaculatus series phylogenetically splits into northern, middle and southern islands, it is tempting to interpret this as an earlier-to-later colonization sequence from north to south down the Lesser Antillean chain (Stenson et al., 2004). However, given that 1) the younger arc did not exist at the origin of either of the series, and 2) that the species involved in the early inter-island colonization sequence no longer exist, attempts to reconstruct these early stages (Stenson et al., 2004; Losos, 2009) are inevitably spurious.

Although reconstructing the early stages of inter-island colonization may be problematic, recent events, such as paraphyly (where one island species is nested inside another island species) may enable some recent inter-island colonizations to be reconstructed (Fig. 5). Indeed, if no species or haplotypes were lost, one would expect the phylogeny for a radiation to be a complete, sequential, pectinate comb with each species nested inside the next. In fact, paraphyly appears to be relatively rare, the early events being eradicated by lineage loss and species turnover. There are a few examples of species paraphyly established here (the number depending on the arbitrary recognition of allopatric species). The Barbados anole is nested within the nominal (paraphyletic) A. roquet species, and A. sabanus (Saba) and A. desiradei (La Desriade) are nested within the nominal (paraphyletic) A. marmoratus species.

The origin and colonization sequence of the four $A$. roquet lineages on the respective precursor islands of Martinique, and A. extremus from Barbados, are discussed in detail in Thorpe et al. (2010) and SurgetGroba and Thorpe (2013). Barbados appears to have been colonized from the relatively distant Martinique complex (Fig. 5), being a sister lineage to the central Martinique lineage within the roquet Martinique complex (Thorpe and Stenson, 2003; Thorpe et al., 2010; Surget-Groba and Thorpe, 2013). The colonization sequence within this complex suggested by Thorpe et al. (2010) and Surget-Groba and Thorpe (2013) is the divergence of the south and southwest $A$. roquet on their respective precursor islands, the colonization of the central Martinique precursor from the south Martinique precursor, the subsequent colonization of Barbados from this central Martinique, and the colonization of the northwest Martinique precursor from the southwest Martinique precursor.
In the marmoratus complex, from the northern bimaculatus series, nominal species on small islands are nested inside a nominal species from a main island complex, with primary lineages that may correspond to precursor islands. Unlike the situation in Martinique where the four lineages correspond very closely with the four precursor islands, here there are two primary parapatric lineages (western and eastern marmoratus) that correspond less closely with the two presumed precursor islands of Basse Terre and Grande Terre. In this case eastern A. marmoratus (primarily Grande Terre) extends substantially into eastern Basse Terre (Fig. 2B, 5). The two main islands, Basse Terre and Grande Terre, currently approach at a narrow, low elevation isthmus, but presumably these were separate islands in the past. While alternative scenarios are possible, the simplest explanation is that the western and eastern lineages diverged on Basse Terre and Grande respectively after about four to six million years ago when they were both emerged separate islands (Fig. 5), and the eastern lineage, based originally in Grande Terre, has subsequently spread into eastern Basse Terre; a similar scenario is seen in Sphaerodactylus fantasticus (Thorpe et al., 2008). Subsequently to this east-west split, La Desirade was colonized from eastern A. marmoratus on Grande Terre, and geographically distant Saba was relatively recently colonized from western $A$. marmoratus on Basse Terre (Fig. 5). It is also reasonable to assume that Petite Terre has recently been colonized by eastern $A$. marmoratus on adjacent Grande Terre, as it is nested within this lineage (Fig. 5). Although the critical populations of $A$. marmoratus (i.e, those involved in the eastern and western marmoratus contact) have not been the subject of similar population genetic research as $A$. roquet (Thorpe et al., 2010), morphological continuity among eastern and western lineage populations (Malhotra, 1992) suggests the situation is the same as in Martinique. Hence, we have nominal species that are nested inside, and are phylogenetically shallower than, the main island primary lineages which are formally treated as conspecific.

Examples of similar cases of paraphyly exist in other Lesser Antillean lizards. For example, west Basse Terre also appears to be the source of the Dominican gecko (Sphaerodactylus fantasticus) as the Dominican population is nested within the western Basse Terre lineage for these geckos (Thorpe et al., 2008), while the Dominican lineage of $S$. festus is nested within the northern Martinique lineage (Surget-Groba and Thorpe, 2013). Multiple sampling of each island species is a prerequisite to expose paraphyly in all these cases. In the bimaculatus series several species are represented by only single samples, so even if paraphyly existed with extant species it would not be exposed by this study.

Without paraphyly, it can be difficult to infer the colonization process, even with sister species. The large-bodied A. richardii (Grenada and Grenadines) and A. griseus (St Vincent) are sister species, but their age is similar (2.4 and 2.1 my respectively) so it is not possible to know whether the colonization direction was from Grenada/Grenadines to St Vincent, or vice versa, or even from a third, now extinct species on another island. Similarly, the islands of the South American coast (Bonaire and Blanquilla), and St Lucia form a distinct lineage in the roquet series (dated by internal divergence at around 23 mybp). While it is reasonable to expect that these offshore S American island were colonized from the Lesser Antilles species, the divergence of this luciae/ bonairensis/blanquillanus clade, and the bonairensis/blanquillanus clade (similarly dated at around 7 mybp) substantially predates the age of $A$. luciae precluding it as the colonizer. Given the suspected species turnover, the colonizer of these S. American islands could have come from any of the (presumably) Lesser Antilles occupied at the time by members of this clade of the roquet series.

\subsection{Potential dispersal outcomes}

After the initial colonization of an island arc from the mainland (Step 1) the colonizer may disperse through the archipelago (Step 2). It is clear that in Lesser Antillean anoles, and we expect in other 


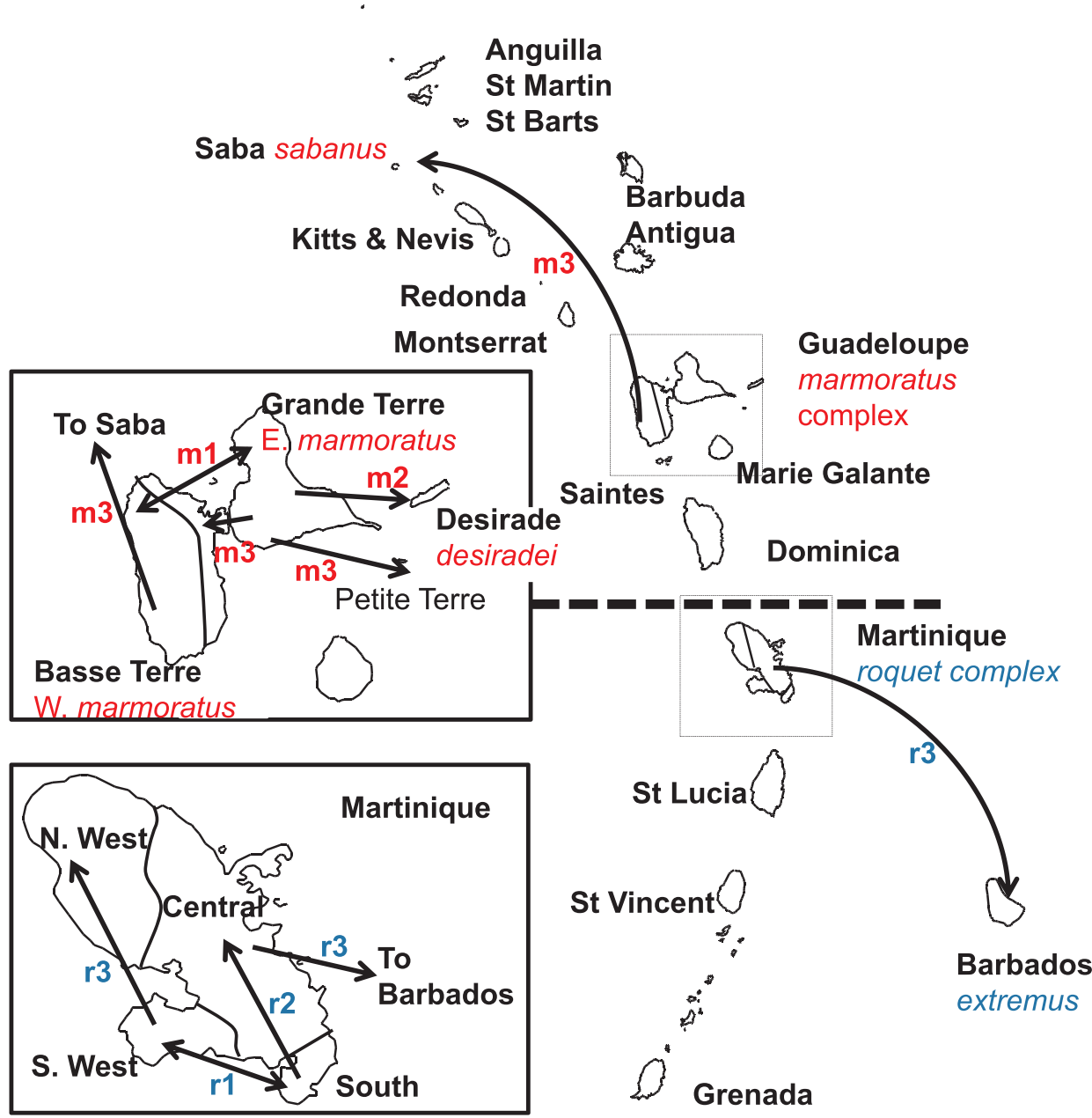

Fig. 5. Relatively recent colonization events of anoles in the Lesser Antilles suggested by paraphyly. There are two long-distance events (colonization of Saba and Barbados) and a series of short distance colonizations from large islands to adjacent smaller islands/islets. In the marmoratus complex there is dispersal (m1) between Basse Terre and Grande Terre and subsequent divergence between these allopatric lineages, then (m2) La Desirade is colonized from Grande Terre. More recently, (m3) Saba is colonized from the Basse Terre's western marmoratus lineage, Petite Terre is colonized from the Grande Terre's eastern marmoratus lineage, and the eastern marmoratus lineage spreads into eastern Basse Terre. In the roquet complex there is dispersal (r1) between south and southwest Martinique precursor islands and subsequent divergence between these allopatric lineages. Then (r2) the central Martinique precursor is colonized from south Martinique. Subsequently (m3), the NW Martinique precursor island is colonized from the SW precursor and Barbados is colonized from the central Martinique precursor. Finally the Martinique precursor islands join to form the current day Martinique. radiations, Step 2 is not simply a question of the original colonizer dispersing to a series of empty islands in sequence. In the potential colonization of an unoccupied island, the two possible outcomes would be success or failure. We have no evidence on how frequently natural extinction of these species occurs, without congeneric competition, leaving islands unoccupied. However, given the high population densities and the current occupation of every island, perhaps most colonization attempt will be from one occupied island to another. And here we postulate five potential outcomes from such a process.

(A) The colonizing species is reproductively isolated from the resident species and becomes extinct due to stochastic early extinction, or being out-competed by the resident. It is axiomatic that this can leave no obvious biogeographic signature, even if it is a frequent outcome.

(B) The colonizing species (small founder population) interbreeds freely with the resident species, resulting in introgression. The colonizer may leave no obvious genetic signature if the colonizer's genes are too rare to be detected, or are lost due to drift or negative selection. The evidence that allopatry over substantial time does not necessarily result in reproductive isolation (Thorpe et al., 2010) suggests this may be a very frequent outcome. An example of this may be the Caravelle Peninsular population of A. roquet, as it is the only Martinique precursor island population without its own distinct genetic lineage. It appears that when this precursor island joined the central Martinique region its anole population was replaced by the central Martinique population. Given the general lack of reproductive isolation among these precursors (Thorpe et al., 2010) it is likely to be introgression rather than an example of process A above, except if the Caravelle Peninsula was occupied by a different species, very divergent from the roquet complex.

(C) The colonizing species (very large founder population or island coalescence) interbreeds to varying extents with the other or resident species, resulting in varying degrees of introgression, but recognition as a single nominal species. This leaves a genetic and biogeographic signature and each anole series in the Lesser Antilles appears to provide an example of this. The extent of introgression between the four precursor Martinique island populations of the nominal species A. roquet, is an example (Thorpe et al., 2010; Surget-Groba et al., 2012). The colonization of eastern Basse Terre from adjacent Grande Terre by the eastern A. marmoratus lineage may be an example of a large founder population, or past island coalescence.

(D) The colonizing species is reproductively isolated from the resident and outcompetes and replaces the resident. The ongoing invasion of A. cristatellus in Dominica and its replacement of the similar (intermediate) sized, syntopic, resident $A$. oculatus in the south west of the island is direct evidence of at least the first stage of this process (Eales et al., 2010; Malhotra et al., 2007). This is also what is inferred for the St Lucian populations (see above), and may have occurred frequently on the older arc islands. Theories, such as size assortment (Losos, 2009), suggest that an intermediate (solitary) anole could not successfully invade when an island is already occupied by an anole of the same size, but the evidence here does not support this.

(E) The colonizing species is reproductively isolated from the resident species and survives and coexists in sympatry with it (Step 4). In the north of the northern Lesser Antilles the sympatry of the 
smaller-bodied wattsi group with the relatively larger bimaculatus series provides an example. In the south of the southern Lesser Antilles the species pairs on Grenada (A. aeneus -smaller, A. richardii -larger) and St Vincent (A. trinitatis -smaller, A. griseuslarger) provide additional examples. The estimated age of the species suggests that the smaller A. trinitatis was the resident in St Vincent before the colonization by $A$. griseus. In Grenada the estimated age of the species are closer and overlap, but the larger $A$. richardii is slightly older and may perhaps have been the resident while A. aeneus was the colonizer. It is not possible to know the extent of sympatry in the past, or if these islands are currently saturated with sympatric pairs. One likely case is Marie Galante which has a large anole (A. ferreus), but no smaller partner. It is not apparent why some islands have two species and some just one. There is a geographic trend, with the southern islands of the south series, and some northern islands of the north series having two species, while the central islands in the chain (both series) have just a single species. However, this does not appear to have anything to do with the age of the current extant species, island age, or island size.

We can gain an insight into the relative frequency of types C (introgression) and $\mathrm{D} / \mathrm{E}$ (replacement/sympatry) by dating the outcomes from island coalescence, natural sympatry and artificial (invasive species) sympatry. The secondary contact after the coalescence of precursor island populations from Martinique, even after about 8 my of divergence (Table 1), show widespread introgression of varying degrees, and always more than across ecotones within a single lineage (Thorpe et al., 2010). Even at about 10 my divergence the invasive species of A. aeneus and A. trinitatis in Trinidad show some hybridization (Hailey et al., 2009). However, the naturally occurring sympatry on St Vincent (A. trinitatis, A. griseus) and Grenada (A. richardii, A. aeneus) occurs after about 15 and 20 my divergence respectively. Similarly, there is no introgression between the invasive $A$. extremus and resident $A$. luciae on St Lucia after about 32 my divergence (Giannassi et al., 1997). In the northern Lesser Antilles the small-bodied wattsi group is naturally sympatric with the larger bodied bimaculatus series. Since the wattsi group and bimaculatus series are reciprocally monophyletic (Poe et al., 2017) their divergence must be greater (perhaps much greater) that the within-bimaculatus series divergence of $22 \mathrm{my}$. Hence, it appears that allopatric isolation does not rapidly result in reproductive isolation and that $>8$, but $<15 \mathrm{my}$ of divergence, is required to achieve this. Consequently, for these anole radiations, introgression is a far more likely outcome in the first half of the radiation process, than replacement or sympatry if the colonized island is already occupied.

\subsection{Conclusions from the island radiation model and Lesser Antillean anoles}

One can infer several stages of the radiation model in the Lesser Antillean anole radiations.

Step 1, the initial colonization (the southern roquet series radiation from S. America, the northern bimaculatus series from the Greater Antilles) is uncontroversial. Step 2, inter-island dispersal can be inferred for relatively recent events e.g., Barbados from Martinique at circa 3 mybp, (or even later in precursor island coalescence), but is opaque, or overwritten by species turnover, in the early stages of the radiation (i.e., 8-32 mybp). The phylogeographic and quantitative trait divergence within an island species (Step 3) is well documented (Thorpe et al., 2015 and references therein), but a very long time (in excess of $8 \mathrm{my}$ ) is required for reproductive isolation. Step 4, (sympatry) is evidenced in a few instances, but these are all quite old (the youngest at 15 my divergence), never involve more than two species, and are inferred to occur only in the second half of the radiation process.
The genus Anolis sensu Losos (2009) is regarded as the most speciose amniote genus with around 400 extant species. This study suggests that, at least in the case of the Lesser Antilles and associated islands, estimates based on extant species may greatly under-estimate the number of species and diversity through geological time. However, this may not reflect the situation in the larger islands of the Greater Antilles, where extinction rates at equilibrium in these multispecies anole communities may be low (Rabosky and Glor, 2010).

\section{Declaration of interest}

None.

\section{Acknowledgements}

We wish to thank the numerous authorities in the Lesser Antilles and associated islands for their support, Jonathan Losos and anonymous reviewers for their comments on an earlier version of this work and Ted Townsend for his help in molecular dating.

\section{Funding}

Data for this work was accumulated over a prolonged period, the very latter stages being supported by an award from The Leverhulme Trust (RF/2/RFG/2010/0008) to R.S.T.

\section{Appendix A. Supplementary material}

Supplementary data associated with this article can be found, in the online version, at https://doi.org/10.1016/j.ympev.2018.06.014.

\section{References}

Aljanabi, S., Martinez, I., 1997. Universal and rapid salt-extraction of high quality genomic DNA for PCR-based techniques. Nucl. Acid. Res. 15, 4692-4693.

Bender, M.L., Fairbanks, R.G., Taylor, F.W., Matthews, R.K., Goddard, J.G., Broecker, W.S., 1979. Uranium-series dating of the Pleistocene reef tracts of Barbados, WestIndies. Geol. Soc. Amer. Bull. 90, 577-594. http://dx.doi.org/10.1130/00167606(1979) $90<577:$ udotpr $>2.0$. co; 2 .

Bochaton, C., Bailon, S., Herrel, A., Grouard, S., Ineich, I., Tresset, A., Cornette, R., 2017. Human impacts reduce morphological diversity in an insular species of lizard. Proc. Roy. Soc. B: Biol. Sci. 284, 20170921. http://dx.doi.org/10.1098/rspb.2017.0921.

Bouysse, P., 1984. The Lesser Antilles island-arc-structure and geodynamic evolution. Initial Reports Deep Sea Drill Project 78, 83-103.

Briden, J.C., Rex, D.C., Faller, A.M., Tomblin, J.-F., 1979. K-Ar geochronology and palaeomagnetism of volcanic rocks in the Lesser Antilles Island arc. Phil. Trans. Roy. Soc. A: Math. Phys. Sci. 291, 485-528.

Creer, D.A., de Queiroz, K., Jackman, T.R., Losos, J.B., Larson, A., 2001. Systematics of the Anolis roquet series of the Southern Lesser Antilles. J. Herpetol. 35, 428-441.

Crottini, A., Madsen, O., Poux, C., Strauß, A., Vieites, D.R., Vences, M., 2012. Vertebrate time-tree elucidates the biogeographic pattern of a major biotic change around the KT boundary in Madagascar. Proc. Natl. Acad. Sci. USA 109, 5358-5363.

Drummond, A.J., Suchard, M.A., Xie, D., Rambaut, A., 2012. Bayesian Phylogenetics with BEAUti and the BEAST 1.7. Mol. Biol. Evol. 29, 1969-1973.

Dubey, S., Shine, R., 2010. Geographic variation in the age of temperate-zone reptile and amphibian species: southern Hemisphere species are older. Biol. Lett. http://dx.doi. org/10.1098/rsbl.2010.0557.

Eales, J., Thorpe, R.S., Malhotra, A., 2010. Colonization history and genetic diversity: adaptive potential in early stage invasions. Mol. Ecol. 19, 2858-2869.

Giannasi, N., Thorpe, R.S., Malhotra, A., 1997. Introductions of Anolis species to the island of St. Lucia, West Indies: testing for hybrids using multivariate morphometrics. J. Herpetol. 31, 586-589.

Glor, R.E., Gifford, M.E., Larson, A., Losos, J.B., Schettino, L.R., Lara, A.R.C., Jackman, T.R., 2004. Partial island submergence and speciation in an adaptive radiation: a multilocus analysis of the Cuban green anoles. Proc. Roy. Soc. B: Biol. Sci. 271, 2257-2265.

Hailey, A., Quesnel, V.C., Boos, H.E.A., 2009. The persistence of Anolis trinitatis as a naturalized lizard in Trinidad against hybridization pressure with Anolis aeneus. Appl. Herpetol. 6, 275-294.

Kemp, M., Hadly, E., 2016. Early Holocene turnover, followed by stability, in a Caribbean lizard assemblage. Quat. Res. 85, 255-261. http://dx.doi.org/10.1016/j.yqres.2015. 12.007.

Leaché, A.D., 2009. Species tree discordance traces to phylogeographic clade boundaries in North American fence lizards (Sceloporus). Syst. Biol. 58, 547-559.

Losos, J.B., 2009. Lizards in an Evolutionary Tree. University of California Press, 
Berkeley, CA.

Losos, J.B., Ricklefs, R.E., 2009. Adaptation and diversification on islands. Nature 457, 830-836.

Malhotra, A., Thorpe, R.S., 1991. Experimental detection of rapid evolutionary response in natural lizard populations. Nature 353 (347), 348.

Malhotra, A., 1992. What Causes Geographic Variation: A Case Study of Anolis oculatus. University of Aberdeen PhD dissertation.

Malhotra, A., Thorpe, R.S., Hypolite, E., James, A., 2007. A report on the status of the herpetofauna of the Commonwealth of Dominica, West Indies. Appl. Herpetol. 4, 177-194.

Malhotra, A., Thorpe, R.S., 2000. The dynamics of natural selection and vicariance in the Dominican anole: patterns of within-island molecular and morphological divergence. Evolution 54, 245-258.

Martin-Kaye, P.H.A., 1969. A Summary of the Geology of the Lesser Antilles. HM Stationery Office.

Maury, R.C., Westbrook, G.K., Baker, P.E., Bouysse, P., Westercamp, D., 1990. Geology of the Lesser Antilles. In: Dengo, G., Case, J.E. (Eds.), The geology of North America. Geological Society of America, Boulder, CO., pp. 141-166.

Meiri, S., 2016. Small, rare and trendy: traits and biogeography of lizards described in the 21st century. J. Zool. 299, 251-261.

Miller, M.A., Pfeiffer, W., Schwartz, T., 2010. Creating the CIPRES Science Gateway for inference of large phylogenetic trees. In: Proceedings of the Gateway Computing Environments Workshop (GCE), 14 Nov. 2010, New Orleans, LA. pp. 1-8.

Myers, N., Mittermeier, R.A., Mittermeier, C.G., da Fonseca, G.A.B., Kent, J., 2000. Biodiversity hotspots for conservation priorities. Nature 403, 853-858.

Nicholson, K.E., Glor, R.E., Kolbe, J.J., Larson, A., Blair Hedges, S., Losos, J.B., 2005. Mainland colonization by island lizards. J. Biogeog. 32, 929-938.

Nicholson, K.E., Crother, B.I., Guyer, G., Savage, J.M., 2012. It is time for a new classi fication of anoles (Squamata: Dactyloidae). Zootaxa 2477, 1-108.

Pavlidis, Alachiotis, 2017. J. Biol. Res.-Thessaloniki 24, 7.

Poe, S., 2013. 1986 Redux: New genera of anoles (Squamata: Dactyloidae) are unwarranted. Zootaxa 3626, 295-299. http://dx.doi.org/10.11646/zootaxa.3626.2.7.

Poe, S., Torres-Carvajal, O., De Queiroz, K., Velasco, J.A., Truett, B., Gray, L.N., Ryan, M.J., Köhler, G., Ayala-Varela, F., Latella, I., 2017. A phylogenetic, biogeographic, and taxonomic study of all extant species of Anolis (Squamata; Iguanidae). Syst. Biol.. http://dx.doi.org/10.1093/sysbio/syx029.

Prates, I., Rodrigues, M.T., Melo-Sampaio, P.R., Carnaval, A.C., 2015. Phylogenetic relationships of Amazonian anole lizards (Dactyloa): taxonomic implications, new insights about phenotypic evolution and the timing of diversification. Mol. Phylo. Evol. $82,258-268$.

Prothero, D.R., 2014. Species longevity in North American fossil mammals. Integ. Zool. 9, 383-393.

Rabosky, D.L., Glor, R.E., 2010. Equilibrium speciation dynamics in a model adaptive radiation of island lizards. Proc. Natl. Acad. Sci. USA 107, 22178-22183. http://dx. doi.org/10.1073/pnas.1007606107.

Rambaut, A., Suchard, M.A., Xie, D., Drummond, A.J., 2014. Tracer v1.6. Available from: < http://beast.bio.ed.ac.uk/Tracer >

Reynolds, R.G., Strickland, T.R., Kolbe, J.J., Falk, B.G., Perry, G., Revell, L.J., Losos, J.B., 2017. Archipelagic genetics in a widespread Caribbean anole. J. Biogeogr. 44, 2631-2647. http://dx.doi.org/10.1111/jbi.13072.

Ricklefs, R., Bermingham, E., 2007. The West Indies as a laboratory of biogeography and evolution. Phil. Trans. Roy. Soc. B: Biol. Sci. http://dx.doi.org/10.1098/rstb.2007.
2068.

Roobol, M.J., Smith, A.L., 2004. Volcanology of Saba and St. Eustatius, Northern Lesser Antilles. Royal Netherlands Academy of Arts and Sciences, Amsterdam.

Hoegg, S., Vences, M., Brinkmann, H., Meyer, A., 2004. Phylogeny and comparative substitution rates of frogs inferred from sequences of three nuclear genes. Mol. Biol. Evol. 21, 1188-1200.

Speed, R., 1994. Barbados and the Lesser Antilles forearc. In: Donovan, S.K., Jackson, T.A. (Eds.), Caribbean Geology: An Introduction. University of the West Indies, Kingston, Jamaica, pp. 179-192.

Stamatakis, A., 2014. RAxML version 8: a tool for phylogenetic analysis and post-analysis of large phylogenies. Bioinformatics 30, 1312-1313. http://dx.doi.org/10.1093/ bioinformatics/btu033.

Stenson, A.G., Thorpe, R.S., Malhotra, A., 2004. Evolutionary differentiation of bimaculatus group anoles based on analyses of mtDNA and microsatellite data. Mol. Phylo. Evol. 32, 1-10.

Surget-Groba, Y., Johansson, H., Thorpe, R.S., 2012. Synergy between Allopatry and Ecology in Population Differentiation and Speciation. Int. J. Ecol. 2012, 10. http:// dx.doi.org/10.1155/2012/273413.

Surget-Groba, Y., Thorpe, R.S., 2013. A likelihood framework analysis of an island radiation: phylogeography of the Lesser Antillean gecko Sphaerodactylus vincenti, in comparison with the anole Anolis roquet. J. Biogeog. 40, 105-116.

Tamura, K., Peterson, D., Peterson, N., Stecher, G., Nei, M., Kumar, S., 2011. MEGA5: molecular evolutionary genetics analysis using maximum likelihood, evolutionary distance, and maximum parsimony methods. Mol. Biol. Evol. 28, 2731-2739.

Thorpe, R.S., Stenson, A.G., 2003. Phylogeny, paraphyly and ecological adaptation of the colour and pattern in the Anolis roquet complex on Martinique. Mol. Ecol. 12, 117-132.

Thorpe, R.S., Leadbeater, D.L., Pook, C.E., 2005. Molecular clocks and geological dates: cytochrome b of Anolis extremus substantially contradicts dating of Barbados emergence. Mol. Ecol. 14, 2087-2096.

Thorpe, R.S., Jones, A., Malhotra, A., Surget-Groba, Y., 2008. Adaptive radiation in Lesser Antillean lizards: molecular phylogenetics and species recognition in the Lesser Antillean dwarf gecko complex, Sphaerodactylus fantasticus. Mol. Ecol. 17, 1489-1504.

Thorpe, R.S., Surget-Groba, Y., Johansson, H., 2010. Genetic tests for ecological and allopatric speciation in anoles on an island archipelago. PLoS Genetics. 6, e1000929.

Thorpe, R.S., Barlow, A., Malhotra, A., Surget-Groba, Y., 2015. Widespread parallel population adaptation to climate variation across a radiation: implications for adaptation to climate change. Mol. Ecol. 24, 1019-1030.

Thorpe, R.S., 2017. Predictability in evolution: adaptation of the Bonaire anole (Anolis bonairensis) to an extreme environment. PLoS ONE 12 (5), e0176434. http://dx.doi. org/10.1371/journal.pone.0176434.

Townsend, T.M., Alegre, R.E., Kelley, S.T., Wiens, J.J., Reeder, T.W., 2008. Rapid development of multiple nuclear loci for phylogenetic analysis using genomic resources: an example from squamate reptiles. Mol. Phylo. Evol. 47, 129-142.

Townsend, T.M., Mulcahy, D.G., Noonan, B.P., Sites, J.W., Kuczynski, C.A., Wiens, J.J., Reeder, T.W., 2011. Phylogeny of iguanian lizards inferred from 29 nuclear loci, and a comparison of concatenated and species-tree approaches for an ancient, rapid radiation. Mol. Phylo. Evol. 61, 363-380.

Wadge, G., 1994. The Lesser Antilles. In: Donovan, S.K., Jackson, T.A. (Eds.), Caribbean Geology: An Introduction. University of the West Indies, Kingston, Jamaica, pp. $167-177$. 